\title{
Bone Mineral Density and Body Composition in Men With Multiple Sclerosis Chronically Treated With Low-Dose Glucocorticoids
}

\author{
V. ZIKÁN ${ }^{1}$, M. TÝBLOVÁ ${ }^{2}$, I. RAŠKA JR. ${ }^{1}$, E. HAVRDOVÁ ${ }^{2}$, M. LUCHAVOVÁ ${ }^{1}$, \\ D. MICHALSKÁ ${ }^{1}$, A. A. KUBĚNA ${ }^{3}$
}

${ }^{1}$ Third Department of Medicine, Department of Endocrinology and Metabolism, General University Hospital and First Faculty of Medicine, Charles University, Prague, Czech Republic, ${ }^{2}$ Department of Neurology, General University Hospital and First Faculty of Medicine, Charles University, Prague, Czech Republic, ${ }^{3}$ Department of Social and Clinical Pharmacy, Faculty of Pharmacy, Charles University, Hradec Králové, Czech Republic

Received December 9, 2011

Accepted May 18, 2012

On-line June 6, 2012

\section{Summary}

The aim of the study was to compare the bone mineral density (BMD) and body composition between ambulatory male MS patients and control subjects and to evaluate the relationships among body composition, motor disability, glucocorticoids (GC) use, and bone health. Body composition and BMD were measured by dual-energy X-ray absorptiometry in 104 ambulatory men with MS (mean age: 45.2 years) chronically treated with low-dose GC and in 54 healthy age-matched men. Compared to age-matched controls, MS patients had a significantly lower total body bone mineral content (TBBMC) and BMD at all measured sites except for the radius. Sixty five male MS patients $(62.5 \%)$ met the criteria for osteopenia and twenty six of them (25\%) for osteoporosis. The multivariate analysis showed a consistent dependence of bone measures (except whole body BMD) on BMI. The total leg lean mass $\%$ was as an independent predictor of TBBMC. The Expanded Disability Status Scale (EDSS), cumulative GC dose and age were independent determinants for BMD of the proximal femur. We conclude that decreasing mobility in male MS patients is associated with an increasing degree of osteoporosis and muscle wasting in the lower extremities. The chronic low-dose GC treatment further contributes to bone loss.

\section{Key words}

Bone mineral density • Body composition - Multiple sclerosis • Osteoporosis • Glucocorticoid treatment

\section{Corresponding author}

V. Zikán, Third Department of Medicine, Department of Endocrinology and Metabolism, General University Hospital and First Faculty of Medicine, Charles University, U Nemocnice 1, Prague 2, 128 08, Czech Republic. Fax: 00420224919780. E-mail: vit.zikan@vfn.cz

\section{Introduction}

Multiple sclerosis (MS) is a chronic inflammatory and progressive disease affecting the myelin sheath covering nerve fibers in the brain and spinal cord, leading to functional impairments such as abnormal walking mechanics, visual impairment, poor balance, muscle weakness, fatigue and progressive immobilization (Compston and Coles 2008). Impaired mobility or lack of weight-bearing physical activity reduces the mechanical stress on bone, which causes a marked imbalance in bone remodeling with a disruption of osteocytes network (Hughes and Petit 2010). Secondary osteoporosis may develop and low-trauma fractures may occur more frequently in patients with MS than in healthy controls (Sibley et al. 1991, Troiano et al. 1992, Cosman et al. 1994, 1998, Nieves et al. 1994, Weinstock-Guttman et al. 2004, Logan et al. 2008, Marrie et al. 2009).

The progressive immobilization is likely to be the main factor that influence bone health in patients with MS. The Kurtzke Expanded Disability Status Scale 
(EDSS), a method quantifying disability of MS patients (Kurtzke 1983), has been found to negatively correlate with bone mineral density (BMD) (Sibley et al. 1991, Cosman et al. 1994, Schwid et al. 1996, WeinstockGuttman et al. 2004, Ozgocmen et al. 2005, Hotermans et al. 2006, Terzi et al. 2010), mainly at the hip (Hotermans et al. 2006). In addition, a strong relationship between the EDSS and total body muscle mass has been observed in female patients with MS (Formica et al. 1997); however, there was no significant correlation between muscle mass and EDSS in fully ambulatory MS patients (Sioka et al. 2011). The body composition seems to have an important influence on bone mass in non - MS populations (Proctor et al. 2000). In MS, the total body muscle mass has been found to be an independent predictor of the total or femoral bone mineral content (Formica et al. 1997, Mojtahedi et al. 2008). Before the era of disease modifying drugs in MS, glucocorticoids (GC) were used not only for the treatment of acute attacks but in some cases also for long-term management as in other autoimmune disorders. This treatment may have a further negative effect on bone remodeling and bone strength (van Staa et al. 2002). For the use of pulsed GC treatment, the prospective studies have demonstrated no evidence of bone loss (Schwid et al. 1996, Bergh et al. 2006) and only two cross-sectional studies in MS patients reported bone loss related to intermittent GC use (Formica et al. 1997, Ozgocmen et al. 2005).

The most of clinical data assessing the bone health in MS patients were obtained largely in women; however, understanding the causes associated with a decreased bone mass in male MS patients, can help to define the optimal gender appropriate therapeutic intervention. In addition, further studies are needed to better define the relationship between bone mass and muscle mass in MS patients with different levels of motor disability. The aim of the present study was: 1) to compare bone mass and body composition indices between ambulatory male patients with MS and control subjects and 2) to investigate the relationships among body composition, motor disability, GC use, and bone health in ambulatory male MS patients.

\section{Methods}

\section{Patients}

One hundred and four male patients with MS (mean age of $45.2 \pm 10.2 \mathrm{y}$ ) followed in the MS center in Prague were selected retrospectively and compared to 54 controls, age and height comparable healthy men (mean age of $44.6 \pm 10.1 \mathrm{y}$ ). Both groups were of Caucasian origin. Descriptive characteristics of MS patients and healthy controls are stated in Table 1. All MS patients were chronically treated with low-dose GC (mean daily dose was $5.0 \pm 2.7 \mathrm{mg}$ of prednisone equivalent) and had an EDSS score ranging from 1 to 6.5 (mean $4.4 \pm 1.8$ ). In addition, pulsed pharmacological doses of $\mathrm{GC}$ were administered intravenously ( $1 \mathrm{~g}$ of methylprednisolone per day for 3-5 days) occasionally followed by a 3-4 weeks of oral methylprednisolone, depending on the severity of the exacerbations. Exclusion criteria for both patients and control group were abnormal serum or urinary calcium level, diseases other than osteoporosis that would interfere with bone metabolism; or use of any other medication affecting bone metabolism (except to GC) within the 12 months prior the selection, such as bisphosphonates (e.g. p.o. bisphosphonate treatment for more than 3 years or parenteral bisphosphonates), raloxifene, strontium ranelate, cyclosporine, fluoride, or thiazide diuretics. The patients with MS were recruited from the Multiple Sclerosis Center of the General University Hospital in Prague, while the age-comparable controls were selected from a cohort of healthy subjects recruited from the Bone Center of General University Hospital in Prague for the preventive bone program. The study was undertaken with the understanding and written consent of each subject, with the approval of the Ethics Committee of the General University Hospital, and complied with national legislation and the Code of Ethical Principles for Medical Research Involving Human Subjects of the World Medical Association (Declaration of Helsinki).

Patients with MS were divided into two groups according to the EDSS, a scale used to measure neurological status and disability. EDSS in its central and lower portion is based upon the ability to walk that is important for normal bone remodeling (Kitagawa and Nakahara 2008, Martyn-St James and Carroll 2008). For purposes of the study, patients were characterized as ambulatory if their EDSS score was $\leq 6.5$. Patients with EDSS $<6.0$ are ambulatory (walking without assistance) and EDSS value of 6.0 and 6.5 are considered walking only several meters with unilateral or bilateral support, mostly within the flat. Patients with EDSS $\geq 7$ are considered non-ambulatory (only the ability of transfer to wheelchair from the bed is preserved) and these patients were not included in the present study. 


\section{Anthropometric measures}

Standing height and weight measurements were completed with participants wearing lightweight clothing and no shoes. Height was obtained with a stadiometer. Weight was measured on a calibrated digital scale.

\section{Body composition and bone measures}

BMD was measured at the lumbar spine (L1-L4), total femur, femoral neck and whole body in all participants. In addition, the BMD at the distal (1/3) radius was measured in a part of the patients. The BMD and total body bone mineral content (TBBMC) was determined using a dual energy X-ray absorptiometry (DXA) densitometer (QDR 4500 A, Hologic Inc., Waltham, MA, USA; software v. APEX 3.0). Patients and control group were measured on the same densitometer. The short-term precision in vivo errors for the lumbar spine (L1-L4), total femur, femoral neck, distal radius were $0.7 \%, 0.9 \%, 1.9 \%$ and $2.1 \%$, respectively; the long-term precision in vitro error was $0.32 \%$. We measured body-composition variables from the whole body scan. The CVs for fat and lean mass by DXA are $1.9 \%$ and $2.6 \%$, respectively, for our site. Taking into account the large variation of body composition parameters, we expressed the body composition variables as mass percentages. Total and regional body composition variables were calculated as follows:

Percentage of total body fat mass $(\mathrm{FM} \%)=$ total body fat mass/ whole body mass x 100

Percentage of trunk fat (trunk fat $\%$ ) = trunk fat mass/total fat mass $\mathrm{x} 100$

Percentage of total leg fat mass (leg FM \%) = (right leg + left leg fat mass)/total fat mass x 100

Percentage of total arm fat mass (arm FM \%) = (right arm + left arm fat mass)/ total fat mass $\mathrm{x} 100$

Trunk / total leg fat mass ratio (trunk/leg FM) = trunk fat mass/leg fat mass

Percentage of total body lean mass (LM \%) = total body lean mass / whole body mass x 100

Percentage of total leg lean mass (leg LM \%) = (right leg + left leg lean mass)/ total lean mass x 100

Percentage of total arm lean mass (arm LM \%) = (right arm + left arm lean mass)/ total lean mass x 100

The data from the third National Health and Nutrition Examination Survey (NHANES III) were used as the reference sample to calculate the $\mathrm{T}$ score, as recommended by Kanis and Gluer (2000). According to the criterion set by the World Health Organization, a subject was classified as having osteopenia or osteoporosis if lumbar spine and/or proximal femur BMD was below 1.0 ( $\mathrm{T}$ score $<-1.0$ ) or 2.5 standard deviations ( $\mathrm{T}$ score $<-2.5$ ) below the young reference population, respectively (Kanis and Gluer 2000). Gender-specific reference data were used to calculate the $\mathrm{T}$ scores. Data from the NHANES III study were also used to calculate total proximal femur Z-scores, to compare our subjects with the age and gender-matched population. For example, a Z-score of -1 indicates a proximal femur BMD value of 1.0 standard deviation below the age and gender-matched population.

\section{Statistical analysis}

Comparisons between MS patients as a whole group and age-comparable controls were done using Kolmogorov-Smirnov test. Comparisons of subgroups of MS patients and age-comparable controls were performed using multivariate general linear model (GLM) with bootstrap modification. To avoid unnecessary increase in the risk of false positive statistical tests (due to the large number of combinations predictor-dependent variable), we first use linear regression-backward method to exclude those potential predictors that either did not affect significantly any of the dependent variables or all of these affected only indirectly by other predictors. We tested separately the predictors of the category of "body composition indices" (BMI and total body LM \%; total leg LM \%, total leg FM \%, total arm LM \%, total arm FM \%) and the predictors of category of "disease and GC related parameters" (age and disease duration, EDSS score, daily and cumulative GC dose, duration of GC treatment). Remaining predictors of both categories were then tested in the final multivariate GLM with bootstrap modification in order to find independent predictors of dependent variables: TBBMC and BMD at the lumbar spine, total femur, femoral neck and whole body BMD. In addition, multivariate GLM was used to study associations between EDSS and BMI and lean mass indices percentage of total body lean mass (LM \%) and percentage of total leg lean mass (leg LM \%). The statistical significance was defined as an alpha level of 0.05 . We used GLM in order to estimate also the proportion of explained variability and thus the effect size of this dependence $\left(\eta^{2}\right)$. Cohen's convention indicates a large effect size threshold $\eta^{2}>0.137$, medium effect size for $0.137>\eta^{2}>0.0588$ and a small effect size for $0.0588>\eta^{2}>0.0099$ (Cohen 1988). All data analyses were conducted with PASW v. 18.0 (SPSS Inc., Chicago, IL, USA). 


\section{Results}

\section{Study population}

The descriptive characteristics and indices of body composition and BMD of patients and controls are summarized in Table 1 and Table 2, respectively. Patients with MS did not differ from control subjects in age, height, weight or BMI. MS patients were divided into the subgroups according to EDSS score; the patients with EDSS $\geq 6.0$ were significantly older, with a longer duration of disease as well as with a higher daily and cumulative GC dose than had the subgroup with EDSS $<6.0$ (Table 1).

\section{Bone mass indices}

In comparison with age-matched controls, male patients with MS as a whole group had a significantly lower TBBMC and BMD at all measured sites except for the radius (Table 2$)$. Sixty five $(62.5 \%)$ and twenty six (25\%) of male MS patients met criteria for osteopenia and osteoporosis, respectively (Table 3 ). There was a statistically significant negative correlation between EDSS and TBBMC as well as BMD at all measured sites, except for the radius. These results suggest more than two-fold higher prevalence of osteoporosis in MS patients with EDSS $\geq 6.0$ (Table 3). In contrast, patients with EDSS $<6$ did not significantly differ in BMD at the total femur from healthy age-matched controls (Table 2). Five patients in MS group have seven fracture events ( 2 vertebral, one rib and 4 extremities).

\section{Body composition indices}

Body mass index (BMI), which is often used as a surrogate measure of adiposity, was positively correlated with TBBMC as well as with BMD at all measured sites except for the radius, but it does not distinguish between the individual components of weight. There was no significant difference in BMI between subgroups of MS patients and control healthy subjects. However, there was a significant difference in soft tissue composition between MS patients and controls. Regarding adipose indices, percentage of total body fat mass (FM \%) and percentage of total arm FM (arm FM \%) were significantly higher in the patients with MS than in control subjects, whereas percentage of total leg FM (leg FM \%) and trunk FM (trunk FM \%) did not differ. In contrast, compared with age-matched control subjects, patients with MS as a whole group had significantly reduced muscle mass indices percentage of total body lean mass(LM\%) and total leg lean mass (leg LM \%), except for percentage of total arm lean mass (arm LM \%) which was significantly higher. When comparing subgroups of MS patients according to EDSS score, leg LM \%was significantly lower in patients with EDSS $\geq 6$ than in patients with EDSS $<6$ (Table 2).

Table 1. Descriptive characteristics of male patients with MS and healthy control subjects. Data are mean value ( \pm standard deviation).

\begin{tabular}{lcccc}
\hline & Healthy men & \multicolumn{3}{c}{ Men with multiple sclerosis } \\
\cline { 3 - 5 } Variable & $\mathbf{n}=\mathbf{5 4}$ & $\mathbf{n}=\mathbf{1 0 4}$ & $\mathbf{E D S S}<\mathbf{6 . 0}$ & $\mathbf{7 . 0}>\mathbf{E D S S} \geq \mathbf{6 . 0}$ \\
& $\mathbf{n}=\mathbf{6 5}$ & $\mathbf{n}=\mathbf{3 9}$ \\
\hline Age (years) & $44.6(10.1)$ & $45.2(10.2)$ & $43.5(10.8)$ & $48.2(8.4)$ \\
Height $(\mathrm{m})$ & $1.79(0.08)$ & $1.79(0.06)$ & $1.79(0.06)$ & $1.78(0.07)$ \\
Weight $(\mathrm{kg})$ & $81.0(10.2)$ & $78.4(11.7)$ & $80.0(12.5)$ & $75.6(9,8)$ \\
BMI $\left(\mathrm{kg} / \mathrm{m}^{2}\right)$ & $25.4(3.4)$ & $24.5(3.4)$ & $24.9(3.6)$ & $24.0(2.9)$ \\
Duration of disease (years) & - & $15.3(7.2)$ & $13.7(6.6)$ & $17.8(7.5)^{\mathrm{a}}$ \\
Type of disease & - & & & \\
RR-MS & - & 45 & 45 & 0 \\
SP-MS & - & 51 & 16 & 35 \\
PP-MS & - & $9.1(4.4)$ & $7.8(3.6)$ & $11.5(4.8)^{\mathrm{a}}$ \\
Glucocorticoids (years) & - & $5.0(2.7)$ & $4.7(2.6)$ & $5.6(2.7)^{\mathbf{b}}$ \\
Mean dose (mg/day) & - & $21.1(13.7)$ & $17.3(12.2)$ & $28.0(13.8)^{\mathrm{a}}$ \\
Cumulative dose (g) & - & $4.4(1.8)$ & $3.3(1.3)$ & $6.2(0.3)^{\mathrm{a}}$ \\
EDSS score & 12 & 17 & 8 & 9 \\
Smoking & & & 4 & \\
\hline
\end{tabular}

BMI = body mass index; EDSS = Expanded Disability Status Scale; RR -, SP- and PP-MS = relapsing-remitting-, secondary progressiveand primary progressive multiple sclerosis, respectively. Statistical significance between patients subgroups: ${ }^{\mathrm{a}} \mathrm{p}<0.001 ;{ }^{\mathrm{b}} \mathrm{p}<0.01$. 
Table 2. Comparison of the results of the total body bone mineral content (TBBMC) and bone mineral density (BMD) and body composition variables between patients with MS (whole group and subgroups) and healthy control subjects. Data are presented as mean values ( \pm standard deviation).

\begin{tabular}{|c|c|c|c|c|}
\hline \multirow[b]{2}{*}{ Variable } & \multirow{2}{*}{$\begin{array}{l}\text { Healthy men } \\
\qquad \mathbf{n}=54\end{array}$} & \multicolumn{3}{|c|}{ Men with multiple sclerosis } \\
\hline & & $\begin{array}{c}\text { Total } \\
\mathrm{n}=104\end{array}$ & $\begin{array}{c}\text { EDSS } \leq 5.5 \\
n=65\end{array}$ & $\begin{array}{c}\text { EDSS } \geq \mathbf{6 . 0} \\
\mathbf{n}=\mathbf{3 9}\end{array}$ \\
\hline \multicolumn{4}{|l|}{ BMD results: } & $2338.5(411.6) * * *, b$ \\
\hline Lumbar spine $\left(\mathrm{g} / \mathrm{cm}^{2}\right)$ & $1.043(0.130)$ & $0.920(0.127)^{* * *}$ & $0.942(0.145) * * *$ & $0.870(0.130) * * *, \mathrm{~b}$ \\
\hline Lumbar spine (T score) & $-0.5(1.3)$ & $-1.6(1.2)$ & $-1.4(1.4)$ & $-2.0(1.2)$ \\
\hline Lumbar spine (Z score) & $-0.2(1.3)$ & $-1.3(1.2)$ & $-1.1(1.4)$ & $-1.6(1.2)$ \\
\hline Total femur $\left(\mathrm{g} / \mathrm{cm}^{2}\right)$ & $0.991(0.141)$ & $0.882(0.159) * * *$ & $0.938(0.137)$ & $0.773(0.138) * * *, \mathrm{a}$ \\
\hline Total femur (T score) & $-0.3(1.0)$ & $-1.0(1.0)$ & $-0.7(0.8)$ & $-1.7(0.9)$ \\
\hline Total femur (Z score) & $0.1(1.3)$ & $-0.8(1.0)$ & $-0.5(0.8)$ & $-1.3(1.0)$ \\
\hline Femoral neck & $0.827(0.144)$ & $0.737(0.141) * * *$ & $0.772(0.133) *$ & $0.665(0.136) * * *, \mathrm{~b}$ \\
\hline Femoral neck (T score) & $-0.7(1.1)$ & $-1.4(1.1)$ & $-1.2(1.0)$ & $-1.9(1.0)$ \\
\hline Femoral neck (Z score) & $-0.2(1.1)$ & $-0.9(1.0)$ & $-0.7(1.0)$ & $-1.3(1.0)$ \\
\hline Radius $1 / 3\left(\mathrm{~g} / \mathrm{cm}^{2}\right)$ & $0.770(0.068)$ & $0.793(0.062)$ & $0.795(0.06)$ & $0.791(0.072)$ \\
\hline Radius $1 / 3$ (T score) & $-0.9(1.3)$ & $-0.4(1.1)$ & $-0.4(1.1)$ & $-0.3(1.2)$ \\
\hline Radius 1/3 (Z score) & $-0.6(1.3)$ & $0.0(1.1)$ & $0.0(1.1)$ & $0.0(1.1)$ \\
\hline Total body $\left(\mathrm{g} / \mathrm{cm}^{2}\right)$ & $1.247(0.114)$ & $1.117(0.108) * * *$ & $1.139(0.100) * * *$ & $1.064(0.119) * * *, \mathrm{~b}$ \\
\hline Total body (T score) & $0.5(1.1)$ & $-1.0(1.1)$ & $-0.8(1.0)$ & $-1.5(1.2)$ \\
\hline Total body (Z score) & $0.5(1.1)$ & $-0.4(0.9)$ & $-0.2(0.9)$ & $-0.8(1.0)$ \\
\hline \multicolumn{5}{|l|}{ Adipose indices: } \\
\hline Total body FM\% & $25.5(6.4)$ & $29.2(5.1) * *$ & $28.9(5.3)^{* *}$ & $29.7(4.1)^{* *}$ \\
\hline Trunk FM\% & $49.7(6.2)$ & $49.8(5.9)$ & $49.3(6.3)$ & $50.3(5.4)$ \\
\hline Total leg FM\% & $33.4(5.6)$ & $32.7(4.6)$ & $33.2(4.7)$ & $32.1(4.3)$ \\
\hline Total arm FM\% & $11.2(1.2)$ & $11.9(1.2) *$ & $11.9(1.2)^{*}$ & $11.8(1.3)^{*}$ \\
\hline Trunk/leg FM & $1.56(0.5)$ & $1.57(0.4)$ & $1.54(0.5)$ & $1.62(0.4)$ \\
\hline \multicolumn{5}{|l|}{ Lean Mass indices: } \\
\hline Total body LM\% & $70.9(6.2)$ & $67.5(4.8)^{* *}$ & $67.8(5.2)^{* *}$ & $67.1(3.9)^{* *}$ \\
\hline Total leg LM\% & $34.6(2.5)$ & $33.7(1.7)^{*}$ & $34.2(1.6)$ & $32.9(1.6) * * *, \mathrm{~b}$ \\
\hline Total arm LM\% & $12.3(1.1)$ & $13.2(1.0) * * *$ & $13.0(1.0) * *$ & $13.4(1.1) * * *$ \\
\hline
\end{tabular}

Statistical significance between patients vs. control group: $* * * \mathrm{p}<0.001 ; * * \mathrm{p}<0.01 ; * \mathrm{p}<0.05$; and between patients subgroups: ${ }^{a} p<0.001 ;{ }^{b} p<0.01$.

Table 3. Percentages of low BMD patients and healthy controls by EDSS score.

\begin{tabular}{|c|c|c|c|c|}
\hline & \multirow{2}{*}{$\begin{array}{l}\text { Healthy men } \\
\qquad n=54\end{array}$} & \multicolumn{3}{|c|}{ Men with multiple sclerosis } \\
\hline & & $\begin{array}{c}\text { Total } \\
\mathbf{n}=104\end{array}$ & $\begin{array}{c}\text { EDSS }<6.0 \\
n=58\end{array}$ & $\begin{array}{c}\text { EDSS } \geq 6.0 \\
n=46\end{array}$ \\
\hline Normal & $36(66.7 \%)$ & $13(12.5 \%)$ & $13(22.4 \%)$ & $4(8.7 \%)$ \\
\hline Osteopenia & $16(29.6 \%)$ & $65(62.5 \%)$ & $36(62.1 \%)$ & $25(54.3 \%)$ \\
\hline Osteoporosis & $2(3.7 \%)$ & $26(25.0 \%)$ & $9(15.5 \%)$ & $17(37.0 \%)$ \\
\hline
\end{tabular}

Normal: T score $\geq-1.0$; Osteopenia: $-1<\mathrm{T}$ score $>-2.5$; Osteoporosis: $T$ score $\leq-2.5$. 


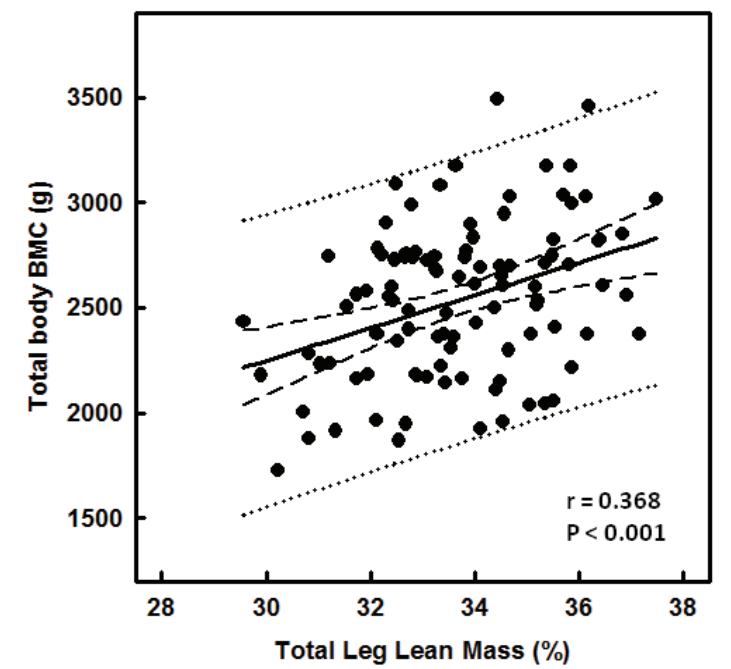

Fig. 1. Relationship between total body bone mineral content ( $\mathrm{g}$ ) and total leg lean mass (\%) in patients with multiple sclerosis. Dotted lines: prediction intervals. In multivariate GLM, total leg lean mass (\%) was positively associated with total body bone mineral content (TBBMC) $\left(p=0.03, \eta^{2}=0.050\right.$; after adjustment for age, BMI, EDSS and cumulative GC dose).

Relationships between BMD, body composition, EDSS and other clinical variables

Linear regression analysis (backward method) of TBBMC and BMD at all measured sites showed a significant dependence on BMI (at all measured sites), total leg LM \% (except for femoral neck BMD), EDSS (except for femoral neck BMD) and cumulative GC dose (except for TBBMC and whole body BMD).

The final multivariate GLM of TBBMC and BMD at all measured sites showed a consistent dependence on BMI (BMD increased with higher BMI, except for the whole body BMD) and on age (decreasing with higher age, except for the lumbar spine BMD). In regard of soft tissue components, the total leg LM \% was positively associated with BMD at lumbar spine, total femur and femoral neck as well as with TBBMC; however, in multivariate GLM, the leg LM \% was an independent predictor of only TBBMC $(p=0.03$; $\left.\eta^{2}=0.050\right)$ (Fig.1).

The EDSS score was negatively associated with BMD at all measured sites, except the radius; however, in multivariate GLM, EDSS score predicted only BMD at the total femur ( $p=0.02, \eta^{2}=0.058$ ) (Fig. 2a). Furthermore, as shown in Figure $2 b$, EDSS score was negatively associated with total leg LM \% $\left(p<0.001, \eta^{2}=0.197\right.$; after adjustment for age and cumulative GC dose). The cumulative GC dose was negatively associated with BMD at lumbar spine, total femur and femoral neck; however, in final multivariate GLM, the cumulative GC
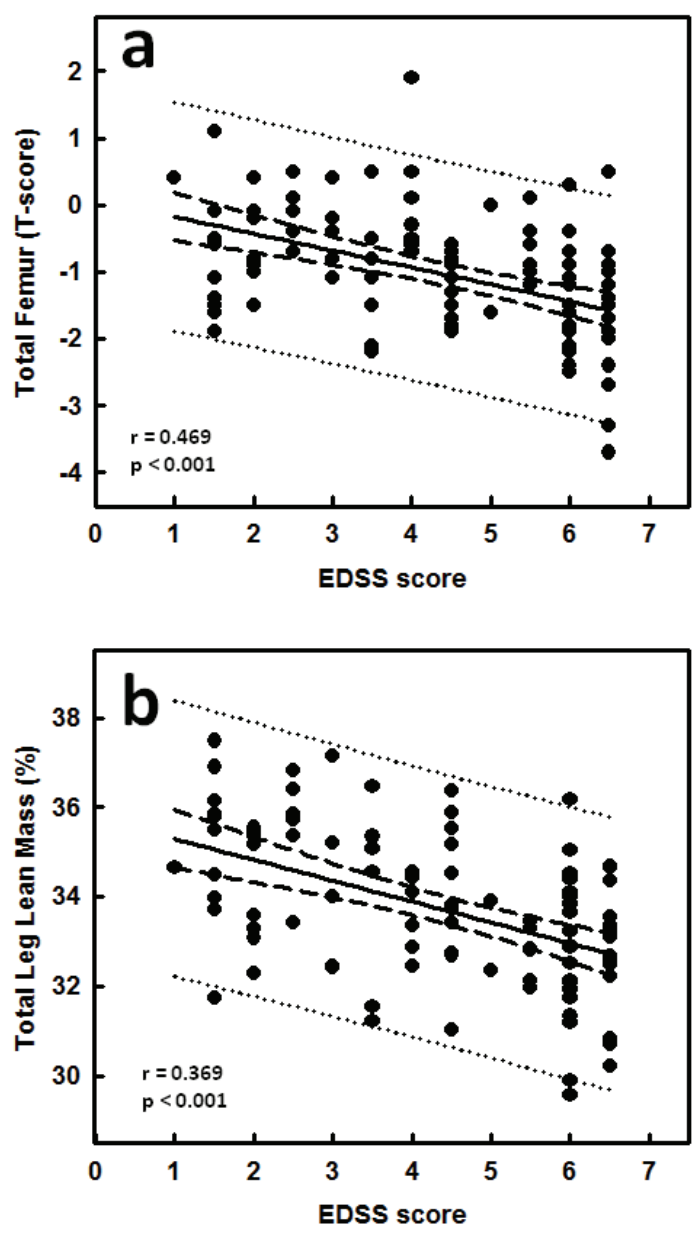

Fig. 2. Bone mineral density at the total femur ( $T$ score) (a) and total leg lean mass (\%) (b) as a function of disability status (EDSS score) in patients with multiple sclerosis. Dotted lines: prediction intervals. In multivariate GLM, EDSS score was negatively associated with BMD at the total femur $(p=0.02$, $\eta^{2}=0.058$; after adjustment for age, BMI, total leg lean mass $\%$ and cumulative GC dose) and with total leg LM \% ( $p<0.001$, $\eta^{2}=0.197$; after adjustment for age and cumulative GC dose).

dose remained as an independent determinant of BMD at the total femur $\left(p=0.02, \eta^{2}=0.064\right)$ (Fig. 3) and femoral neck $\left(p=0.02 ; \eta^{2}=0.063\right)$.

\section{Discussion}

This study demonstrated that ambulatory male MS patients chronically treated with low-dose GC have a significantly lower total body BMC as well as total and regional BMD values as compared with healthy agematched male control subjects. Our results showed a high prevalence of osteoporosis $(25 \%)$ and osteopenia $(62.5 \%)$ in relatively young male MS patients. The multivariate analysis showed that the higher levels of motor disability as well as the low percentage of total leg lean mass and the cumulative GC dose were the main 


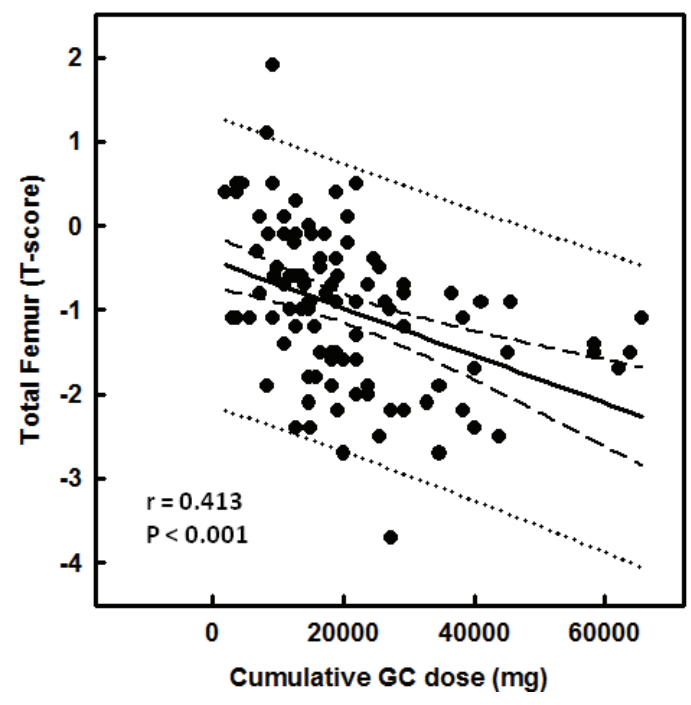

Fig. 3. Relationship between bone mineral density at the total femur (T score) and cumulative glucocorticoid dose (mg). Dotted lines: prediction intervals. In multivariate GLM, the cumulative glucocorticoid dose was negatively associated with BMD at the total femur $\left(p=0.02, \eta^{2}=0.064\right.$, after adjustment for age, EDSS, BMI and total leg lean mass \%).

factors contributing to bone loss in male MS population.

The severity of bone loss was clearly related to the degree of motor disability as assessed by EDSS score. The ambulatory patients with EDSS $\geq 6.0$ who were unable to walk without assistance had a significantly lower total body BMC and BMD at all measured sites, except for the radius when compared to the healthy controls. There was a more than two-fold higher prevalence of osteoporosis in subgroup with EDSS $\geq 6.0$ (37\% vs. $16 \%$ in subgroup with EDSS <6.0). This is in accordance with the previous study of Weinstock-Guttman et al. (2004) who reported on prevalence of osteoporosis in $37.5 \%$ of male MS patients and mean EDSS score 6.7 in the osteoporotic group. In contrast, our ambulatory patients with EDSS $<6.0$ had no deficits in BMD at the total femur when compared to healthy controls. Similarly Sioka et al. (2011) showed no deficit in bone mass in fully ambulatory patients with MS. In our study, the multivariate analysis confirmed that EDSS score was an independent predictor of BMD at the total femur. This is in an agreement with previous studies which documented a strong negative correlation between disability level, measured by EDSS score and BMD at the proximal femur (Hotermans et al. 2006).

These results suggest that the inability to walk without assistance may be one of the main factors in accelerating bone loss. A reduced mechanical stress on bone causes a marked imbalance in bone remodeling with a transient increase in bone resorption (which occurs initially), and a decrease in bone formation (which is sustained for a longer duration) (Takata et al. 2001). The mechanism causing the bone remodeling imbalance probably lies in a marked disruption of osteocytes network due to increase of osteocyte apoptosis. Osteocytes represents $95 \%$ of all bone cells and form a mechanosensory system which is based on a threedimensional network of tightly interconnected osteocytes entombed in mineralized bone matrix (Rochefort et al. 2010). Disruption of this system affects probably several aspects of bone homeostatic system, such as mechanosensitivity, mechanotransduction, and basic multicellular units responsible for bone remodeling (Tatsumi et al. 2007). The immobilization-induced osteocyte apoptosis is followed by osteoclastogenesis and increased bone resorption (Aguirre et al. 2006). While molecular mechanisms of disuse osteoporosis are not well understood, recent evidence found that mechanical unloading caused up-regulation of Sost gene in osteocytes and increased levels of sclerostin (product of Sost gene) (Lin et al. 2009). Sclerostin is responsible for the inhibition of Wnt/beta-catenin signaling in vivo and for the suppressed viability of osteoblasts and osteocytes (Lin et al. 2009).

The results of the current study are consistent with the findings from a number of previous studies showing that BMD is highly related to body weight or BMI, such that subjects with higher body weight have higher BMD (Nguyen et al. 1994, 1996). Several mechanisms have been suggested regarding the positive association between BMI and BMD, e.g. BMI is considered to contribute to an increase of BMD by imposing higher mechanical load on bone, which stimulates osteogenesis through bone remodeling and leads to an increase in BMD (Frost 1998). However, BMI does not distinguish between the individual components of body weight. Also there was no significant difference in BMI between subgroups of MS patients and control healthy subjects. In contrast, compared with agematched control subjects, patients with MS as a whole group had significantly reduced muscle mass indices percentage of total body lean mass (LM \%) and total leg lean mass (leg LM \%).

Our results showed a significant negative association between EDSS and the total leg LM \%. The total leg LM \% was significantly lower and total arm LM $\%$ was significantly higher in patients with EDSS $\geq 6$ than in the control group, suggesting that in male MS patients, motor disability affects mainly lower extremity muscle mass, whereas upper extremities muscles are preserved. The site-specific effect of motor disability in 
MS patients which results in a loss of lower extremities muscle mass may explain the loss of BMD mainly at proximal femur, while BMD of lumbar spine or distal radius is not decreased because of its adequate mechanical stimulation by the trunk, arms and back muscles in the upright position.

A novel finding of this study is the association between the total leg lean mass and bone health status in males with MS. The multivariate analysis showed that the total leg LM \% was an independent predictor of total body BMC. The absence of a relationship between leg LM \% and BMD in the multivariate analysis may be due to the interaction with other covariates (such as age, BMI or EDSS score) which may counteract the negative effect of the reduced leg lean mass on BMD. We suggest that the site specific effect of reduced leg muscle mass may be influenced e.g. by weight-bearing effect of BMI which promotes an increase in BMD and therefore counteracts the negative effect of the reduced leg lean mass on BMD. More recently, Sioka et al. (2011) found the reduced lower extremities muscle mass in ambulatory female MS patients (but not in males patients) when compared to controls; however, no association between the lower extremities muscle mass and bone mass was observed; although, this was a group of patients with a low level of disability with a mean EDSS score of 2.2 (Sioka et al. 2011). Previous studies have shown that total body muscle mass was an independent predictor of total body BMC or proximal femur BMC in females with MS if also patients with a higher degree of motor deficit were included (Formica et al. 1997, Mojtahedi et al. 2008). The muscle-bone relationship has been found in other non-MS populations, such as middle-aged (van Langendonck et al. 2002) and older adults (Blain et al. 2001). This is the theoretical support for the association of muscle mass on bone mass (Frost et al. 1998, Robling et al. 2009). Furthermore, muscle-released bioactive molecules and genetic factors can also contribute to the regulation of both bone and muscle (Karasik and Kiel 2010).

Our finding that lower extremities muscle mass is an independent determinant of bone mass may have important clinical implications for the design of suitable preventive programs in MS patients. The physical activities and exercises should be directed to improve muscle and bone health in the lower extremities. Previous study in non-MS population showed that a resistive training program may increase muscle mass and improve BMD in the femoral region in healthy young and older adults (Ryan et al. 2004). Short-term exercise programs have demonstrated objective improvements in lower limb muscle strength, functional capacity and walking distance (Dalgas et al. 2009) and a recent meta-analysis showed that exercise training leads to improvement in walking mobility in individuals with MS (Snook et al. 2009). However, to our knowledge, there have been published no long-term studies concerning with possible beneficial effect of exercise on bone health in patients with MS.

This study showed that continuous low-dose GC treatment significantly contributes to the loss of BMD in male patients with MS. We found, based on the GLM multivariate analysis, that the cumulative $\mathrm{GC}$ dose is a significant determinant of BMD at the total femur and femoral neck. It is obvious, that continuous GC therapy will have a greater effect on bone mass than intermittent pulsed GC administration (Tuzun et al. 2003, Zorzon et al. 2005, Bergh et al. 2006, Steffensen et al. 2010). Only two cross-sectional studies in MS patients reported bone loss related to pulsed GC use (Ozgocmen et al. 2005, Formica et al. 1997). Ozgocmen et al. (2005) found that estimated cumulative GC dose was negatively correlated with the femoral trochanteric BMD, although there was no correlation with BMD at the femoral neck or lumbar spine and Formica et al. (1997) found a deficit in total body BMC, which could be caused by a reduction in muscle mass due to GC treatment. In the single study in which MS patients were treated with continuous lowdose prednisolone for a mean duration of 6.2 years (mean dose of $7.3 \mathrm{mg} / \mathrm{day}$ ), there was no correlation between bone loss and treatment duration, mean or cumulative GC dose (Štěpán et al. 2004). However, more importantly, the lack of effect of GC on BMD does not necessarily imply a low fracture risk since studies in non-MS GC users showed that fracture risk is only partly explained by BMD (Steinbuch et al. 2004, Bazelier et al. 2012), implying an effect on bone quality (van Staa et al. 2003). The central pathophysiological mechanism of bone loss during long-term use of $\mathrm{GC}$ is reduced bone formation and bone repair, due to actions that affect osteoblast differentiation and function (Weinstein et al. 1998). GC may also affect the metabolism and function of osteocytes and have pro-apoptotic effects on osteoblasts and osteocytes (Lane et al. 2010). These effects of GC might account for deterioration in bone structural and material properties (including decreased trabecular thickness or reduced bone mineralization and elastic modulus of bone surrounding osteocyte lacunae) and a disproportionate loss of bone strength in relation to bone mass (Hayashi et al. 2005). 
The epidemiological studies in non-MS patients clearly showed that doses as low as $2.5-5 \mathrm{mg}$ of prednisolone equivalents per day can be associated with a 2.5-fold increase in vertebral fractures (van Staa et al. 2002), the risk is greater with higher doses used for prolonged periods (van Staa et al. 2000). The previous studies in non-MS patients showed that the risk of osteoporotic fractures remains slightly increased in patients undergoing cyclic GC treatment at high doses (de Vries et al. 2007); however, the continuous effect of low-dose GC treatment on fracture risk has not been studied in MS populations. In our study we reported 2 clinical vertebral fractures in MS patients; however, we did not examine X-ray in all patients to detect subclinical vertebral fractures. Addressing the question of whether duration of GC treatment along with motor disability in patients with MS increases risk of osteoporotic fractures requires further prospective study.

Besides GC, in pharmaceutical management of MS, immunomodulatory drugs wereused: interferon $\beta$ in $26.9 \%$, low-dose methotrexate in $13.5 \%$ and azathioprine in $34.6 \%$, glatiramer in $5.8 \%$ and natalizumab in $1.9 \%$. The effect of immunomodulatory drugs on bone health in MS is not entirely clear and further investigation with regard to their effects on bone health is needed. Although, no harm effect of low dose methotrexate was observed in patients with MS, several case reports have described associations between pathological non-vertebral fractures and low-dose methotrexate in rheumatoid arthritis patients (Urano et al. 2009). In addition, methotrexate osteopathy, characterized by pain, osteoporosis and micro-fractures, has been very rare observed in patients with low dose metotrexate treatment (Van Der Bijl et al. 2008). Other immune-modifying drugs, such as interferon-beta or azathioprine, which are used in conjunction with GC have not been shown to promote bone loss experimentally or clinically. Contrary, interferon-beta may have favorable effect on bone metabolism in patients with MS, probably due to the inhibitory effect of interferon-beta on osteoclasts development (Abraham et al. 2009); however, if patients with immunomodulatory drugs experience fewer relapses, maintaining mobility levels could potentially impact on bone health indirectly (Shuhaibar et al. 2009).

The present study has several limitations. Our study is cross-sectional; therefore, causality between variables cannot be determined. However, a major strength of our study is that we studied both ambulatory patients with MS as well as non-MS controls. Dual energy X-ray absorptiometry was used to assess total body BMC, BMD and soft tissue composition. This technique has its own limitations. The major limitations of DXA primarily reflect limitations imposed by the 2-dimensional nature of DXA. In addition, e.g. the whole body BMD disproportionately assesses cortical bone compared to the specific metaphyseal scanning sites that contain more cancellous bone. Further techniques, such as peripheral quantitative computed tomography which allows for separate assessment of the trabecular and cortical compartments of the bone, may provide better insight into the trabecular-cortical bone relationships (Sukumar et al. 2012). The advantage is that DXA is a noninvasive and relatively easily accessible tool to assess BMD and body composition in clinical practice. Recently it is also possible for DXA to assess mineral mass and its spatial distribution to calculate cross-sectional structural geometrical parameters which are also related to bone strength (Bonnick 2007).

Another limitation is that the study was not designed to assess additional, humoral or endocrine factors which may contribute to bone loss in MS patients. Patients with MS are more susceptible to vitamin D deficiency due to limited sunlight exposure and a high prevalence of vitamin D insufficiency in MS patients has been observed (Nieves et al. 1994, Hiremath et al. 2009). A low vitamin D state contributes to malabsorption of calcium and secondary hyperparathyroidism may lead to bone loss in patients with MS. Moreover, patients treated with GC will be at greater risk for an imbalance between bone formation and bone resorption and therefore more susceptible to development of osteoporosis due to vitamin D insufficiency/deficiency. Although, in previous studies in MS patients, $25 \mathrm{OH}$ vitamin D levels were not associated with BMD; this may be due to the small numbers of patients included in the previous studies (Tuzun et al. 2003, Weinstock-Guttman et al. 2004, Ozgocmen et al. 2005, Steffensen et al. 2005). Nevertheless, the high prevalence of hypovitaminosis D underscores the need for prospective studies to evaluate the impact of vitamin D supplementation with regard to bone or muscle metabolism. Also, gonadal steroids were not determined. In men, androgens and their estrogenic metabolites are among the key regulators affecting bone mass throughout life (Ongphiphadhanakul et al. 1995) and may also contribute to bone loss in male patients with MS (Wei et al. 1997, Weinstock-Guttman et al. 2004). Low testosterone levels were associated with vertebral fractures in men (Scane et al. 1999). Most studies report that circulating levels of estrogens also decrease as men 
age (Ferrini et al. 1998). However, studies of androgen deficiency in MS population have been limited to smaller clinical trials (Wei et al. 1997, Weinstock-Guttman et al. 2004) and further studies are warranted.

In conclusion, our study in males with MS showed a significant association between decreasing mobility and increasing degree of osteoporosis and muscle wasting, namely in the lower extremities. The deficit in the lower extremities muscle mass as well as continuous low-dose GC treatment may further contribute to bone loss. These results have an important clinical implication for rehabilitation of MS patients suggesting that physical activities and exercise programs should be directed to improve muscle and bone health in the lower extremities.

\section{Conflict of Interest}

There is no conflict of interest.

\section{Acknowledgements}

We thank Jana Křenková and Markéta Urbánková for excellent technical assistance. This work was supported by IGA Ministry of Health of Czech Republic No. NS 10564-3.

\section{References}

ABRAHAM AK, RAMANATHAN M, WEINSTOCK-GUTTMAN B, MAGER DE: Mechanisms of interferon-beta effects on bone homeostasis. Biochem Pharmacol 77: 1757-1762, 2009.

AGUIRRE JI, PLOTKIN LI, STEWART SA, WEINSTEIN RS, PARFITT AM, MANOLAGAS SC, BELLIDO T: Osteocyte apoptosis is induced by weightlessness in mice and precedes osteoclast recruitment and bone loss. J Bone Miner Res 21: 605-615, 2006.

BAZELIER MT, DE VRIES F, BENTZEN J, VESTERGAARD P, LEUFKENS HG, VAN STAA TP, KOCHHENRIKSEN N: Incidence of fractures in patients with multiple sclerosis: the Danish National Health Registers. Mult Scler 18: 622-627, 2012.

BERGH FT, KUMPFEL T, SCHUMANN E, HELD U, SCHWAN M, BLAZEVIC M, WISMULLER A, HOLSBOER F, YASSOURIDIS A, UHR M, WEBER F, DAUMER M, TRENKWALDER C, AUER DP: Monthly intravenous methylprednisolone in relapsing-remitting multiple sclerosis - reduction of enhancing lesions, T2 lesion volume and plasma prolactin concentrations. BMC Neurol 6: 19, 2006.

BLAIN H, VUILLEMIN A, TEISSIER A, HANESSE B, GUILLEMIN F, JEANDEL C: Influence of muscle strength and body weight and composition on regional bone mineral density in healthy women aged 60 years and over. Gerontology 47: 207-212, 2001.

BONNICK SL: Noninvasive assessments of bone strength. Curr Opin EndocrinolDiabetes Obes 14: 451-457, 2007.

COHEN J: Statistical power analysis for the behavioral sciences. 2nd ed. Hillsdale (NJ): Lawrence Erlbaum Associates, 1988.

COMPSTON A, COLES A: Multiple sclerosis. Lancet 372: 1502-1517, 2008.

COSMAN F, NIEVES J, HERBERT J, SHEN V, LINDSAY R: High-dose glucocorticoids in multiple sclerosis patients exert direct effects on the kidney and skeleton. J Bone Miner Res 9: 1097-1105, 1994.

COSMAN F, NIEVES J, KOMAR L, FERRER G, HERBERT J, FORMICA C, SHEN V, LINDSAY R: Fracture history and bone loss in patients with MS. Neurology 51: 1161-1165, 1998.

DALGAS U, STENAGER E, JAKOBSEN J, PETERSEN T, HANSEN HJ, KNUDSEN C, OVERGAARD K, INGEMANN-HANSEN T: Resistance training improves muscle strength and functional capacity in multiple sclerosis. Neurology 73: 1478-1484, 2009.

DE VRIES F, BRACKE M, LEUFKENS HG, LAMMERS JW, COOPER C, VAN STAA TP Fracture risk with intermittent high-dose oral glucocorticoid therapy. Arthritis Rheum 56: 208-214, 2007.

FERRINI RL, BARRETT-CONNOR E: Sex hormones and age: a cross-sectional study of testosterone and estradiol and their bioavailable fractions in community-dwelling men. Am J Epidemiol 147: 750-754, 1998.

FORMICA CA, COSMAN F, NIEVES J, HERBERT J, LINDSAY R: Reduced bone mass and fat-free mass in women with multiple sclerosis: Effects of ambulatory status and glucocorticoid use. Calcif Tissue Int 61: 129-133, 1997. 
FROST HM, FERRETTI JL, JEE WS: Perspectives: some roles of mechanical usage, muscle strength, and the mechanostat in skeletal physiology, disease, and research. Calcif Tissue Int 62: 1-7, 1998.

HAYASHI K, YAMAMOTO M, MURAKAWA Y, YAMAUCHI M, KAJI H, YAMAGUCHI T, SUGIMOTO T: Bone fragility in male glucocorticoid-induced osteoporosis is not defined by bone mineral density. Osteoporos Int 20: 1889-1894, 2009.

HIREMATH GS, CETTOMAI D, BAYNES M, RATCHFORD JN, NEWSOME S, HARRISON D, KERR D, GREENBERG BM, CALABRESI PA: Vitamin D status and effect of low-dose cholecalciferol and high-dose ergocalciferol supplementation in multiple sclerosis. Mult Scler 15: 735-740, 2009.

HOTERMANS C, DIVE D, RINKIN, LEROY M, MALAISE M, MOONEN G, FRANCHIMONT N: Hip bone mineral density is correlated with EDSS in patients with multiple sclerosis. $J$ Neurol 257: 410-418, 2006.

HUGHES JM, PETIT MA: Biological underpinnings of Frost's mechanostat thresholds: the important role of osteocytes. J Musculoskelet Neuronal Interact 10: 128-135, 2010.

KANIS JA, GLÜER CC: An update on the diagnosis and assessment of osteoporosis with densitometry. Committee of Scientific Advisors, International Osteoporosis Foundation. Osteoporos Int 11: 192-202, 2000.

KARASIK D, KIEL DP: Evidence for pleiotropic factors in genetics of the musculoskeletal system. Bone 46: 12261237, 2010.

KITAGAWA J, NAKAHARA Y: Associations of daily walking steps with calcaneal ultrasound parameters and a bone resorption marker in elderly Japanese women. J Physiol Anthropol 27: 295-300, 2008.

KURTZKE JF: Rating neurologic impairment in multiple sclerosis: an expanded disability status scale (EDSS). Neurology 33: 1444-1452, 1983.

LANE NE, YAO W: Glucocorticoid-induced bone fragility. Ann N Y Acad Sci 1192: 81-83, 2010.

LIN C, JIANG X, DAI Z, GUO X, WENG T, WANG J, LI Y, FENG G, GAO X, HE L: Sclerostin mediates bone response to mechanical unloading through antagonizing Wnt/beta-catenin signaling. $J$ Bone Miner Res 10: 1651-1661, 2009.

LOGAN WC JR, SLOANE R, LYLES KW, GOLDSTEIN B, HOENIG HM: Incidence of fractures in a cohort of veterans with chronic multiple sclerosis or traumatic spinal cord injury. Arch Phys Med Rehabil 89: 237-243, 2008.

MARRIE RA, CUTTER G, TYRY T, VOLLMER T: A cross-sectional study of bone health in multiple sclerosis. Neurology 73: 1394-1398, 2009.

MARTYN-ST JAMES M, CARROLL S: Meta-analysis of walking for preservation ofbone mineral density in postmenopausal women. Bone 43: 521-531, 2008.

MOJTAHEDI MC, SNOOK EM, MOTL RW, EVANS EM: Bone health in ambulatory individuals with multiple sclerosis: impact of physical activity, glucocorticoid use, and body composition. J Rehabil Res Dev 45: 851$861,2008$.

NGUYEN TV, KELLY PJ, SAMBROOK PN, GILBERT C, POCOCK NA, EISMAN JA: Lifestyle factors and bone density in the elderly: implications for osteoporosis prevention. J Bone Miner Res 9: 1339-1346, 1994.

NGUYEN TV, EISMAN JA, KELLY PJ, SAMBROOK PN: Risk factors for osteoporotic fractures in elderly men. $\mathrm{Am}$ J Epidemiol 144: 255-263, 1996.

NIEVES J, COSMAN F, HERBERT J, SHEN V, LINDSAY R: High prevalence of vitamin D deficiency and reduced bone mass in multiple sclerosis. Neurology 44: 1687-1692, 1994.

ONGPHIPHADHANAKUL B, RAJATANAVIN R, CHAILURKIT L, PIASEU N, TEERARUNGSIKUL K, SIRISRIRO R, KOMINDR S, PUAVILAI G: Serum testosterone and its relation to bone mineral density and body composition in normal males. Clin Endocrinol (Oxf) 43: 727-733, 1995.

OZGOCMEN S, BULUT S, ILHAN N, GULKESEN A, ARDICOGLU O, OZKAN Y: Vitamin D deficiency and reduced bone mineral density in multiple sclerosis: effect of ambulatory status and functional capacity. $J$ Bone Miner Metab 23: 309-313, 2005.

PROCTOR DN, MELTON LJ, KHOSLA S, CROWSON CS, O'CONNOR MK, RIGGS BL: Relative influence of physical activity, muscle mass and strength on bone density. Osteoporos Int 11: 944-952, 2000.

ROBLING AG: Is bone's response to mechanical signals dominated by muscle forces? Med Sci Sports Exerc 41: $2044-$ 2049, 2009. 
ROCHEFORT GY, PALLU S, BENHAMOU CL: Osteocyte: the unrecognized side of bone tissue. Osteoporos Int 21: 1457-1469, 2010.

RYAN AS, IVEY FM, HURLBUT DE, MARTEL GF, LEMMER JT, SORKIN JD, METTER EJ, FLEG JL, HURLEY BF: Regional bone mineral density after resistive training in young and older men and women. Scand $J$ Med Sci Sports 14: 16-23, 2004.

SCANE AC, FRANCIS RM, SUTCLIFFE AM, FRANCIS MJ, RAWLINGS DJ, CHAPPLE CL: Case-control study of the pathogenesis and sequelae of symptomatic vertebral fractures in men. Osteoporos Int 9: 91-97, 1999.

SCHWID SR, GOODMAN AD, EDWARD PJ, MCDERMOTT MP, MATTSON DH: Sporadic corticosteroid pulses and osteoporosis in multiple sclerosis. Arch Neurol 53: 753-757, 1996.

SHUHAIBAR M, MCKENNA MJ, AU-YEONG M, REDMOND JM: Favorable effect of immunomodulatory therapy on bone mineral density in multiple sclerosis. Ir J Med Sci 178: 43-45, 2009.

SIBLEY WA, BAMFORD CR, CLARK K, SMITH MS, LAGUNA JF: A prospective study of physical trauma and multiple sclerosis. J Neurol Neurosurg Psychiatry 54: 584-589, 1991.

SIOKA C, FOTOPOULOS A, GEORGIOU A, PAPAKONSTANTINOU S, PELIDOU SH, KYRITSIS AP, KALEFEZRA JA: Body composition in ambulatory patients with multiple sclerosis. $J$ Clin Densitom 14: 465-470, 2011.

SNOOK EM, MOTL RW: Effect of exercise training on walking mobility in multiple sclerosis: a meta-analysis. Neurorehabil Neural Repair 23: 108-116, 2009.

STEFFENSEN LH, MELLGREN SI, KAMPMAN MT: Predictors and prevalence of low bone mineral density in fully ambulatory persons with multiple sclerosis. J Neurol 257: 410-418, 2010.

STEINBUCH M, YOUKET TE, COHEN S: Oral glucocorticoid use is associated with an increased risk of fracture. Osteoporos Int 15: 323-328, 2004.

SUKUMAR D, SCHLUSSEL Y, RIEDT CS, GORDON C, STAHL T, SHAPSES SA: Obesity alters cortical and trabecular bone density and geometry in women. Osteoporos Int 22: 635-645, 2011.

ŠTĚPÁN JJ, HAVRDOVÁ E, TÝBLOVÁ M, HORÁKOVÁ D, TICHÁ V, NOVÁKOVÁ I, ZIKÁN V: Markers of bone remodeling predict rate of bone loss in multiple sclerosis patients treated with low dose glucocorticoids. Clin Chim Acta 348: 147-154, 2004.

TAKATA S, YASUI N: Disuse osteoporosis. J Med Invest 48: 147-156, 2001.

TATSUMI S, ISHII K, AMIZUKA N, LI M, KOBAYASHI T, KOHNO K, ITO M, TAKESHITA S, IKEDA K: Targeted ablation of osteocytes induces osteoporosis with defective mechano-transduction. Cell Metab 5: 464475, 2007.

TERZI T, TERZI M, TANDER B, CANTURK F, ONAR M: Changes in bone mineral density and bone metabolism markers in premenopausal women with multiple sclerosis and the relationship to clinical variables. $J$ Clin Neurosci 17: 1260-1264, 2010.

TROIANO RA, JOTKOWITZ A, COOK SD, BANSIL S, ZITO G: Rate and types of fractures in corticosteroid-treated multiple sclerosis patients. Neurology 42: 1389-1391, 1992.

TUZUN S, ALTINTAS A, KARACAN I, TANGUREK S, SAIP S, SIVA A: Bone status in multiple sclerosis: beyond corticosteroids. Mult Scler 9: 600-604, 2003.

URANO W, FURUYA T, INOUE E, TANIGUCHI A, URANO T, KOTAKE S, SEKITA C, INOUE S, HARA M, MOMOHARA S, KAMATANI N, YAMANAKA H: Associations between methotrexate treatment and methylenetetrahydrofolate reductase gene polymorphisms with incident fractures in Japanese female rheumatoid arthritis patients. J Bone Miner Metab 27: 574-583, 2009.

VAN DER BIJL AE, ZIJLSTRA TR, ENGELAGE AH, POSTHUMA BJ, VAN VEEN GJ: Three patients with a fracture during methotrexate use, possibly due to methotrexate osteopathy. Ned Tijdschr Geneeskd 152: 2357-2360, 2008.

VAN LANGENDONCK L, CLAESSENS AL, LEFEVRE J, THOMIS M, PHILIPPAERTS R, DELVAUX K, LYSENS R, VANDEN EYNDE B, BEUNEN G: Association between bone mineral density (DXA), body structure, and body composition in middle-aged men. Am J Hum Biol 14: 735-742, 2002.

VAN STAA TP, LEUFKENS HG, ABENHAIM L, ZHANG B, COOPER C: Oral corticosteroids and fracture risk: relationship to daily and cumulative doses. Rheumatology (Oxford) 39: 1383-1389, 2000. 
VAN STAA TP, LEUFKENS HG, COOPER C: The epidemiology of corticosteroid-induced osteoporosis: a metaanalysis. Osteoporos Int 13: 777-787, 2002.

VAN STAA TP, LAAN RF, BARTON IP, COHEN S, REID DM, COOPER C: Bone density threshold and other predictors of vertebral fracture in patients receiving oral glucocorticoid therapy. Arthritis Rheum 48: 32243229, 2003.

WEI T, LIGHTMAN SL: The neuroendocrine axis in patients with multiple sclerosis. Brain 120: 1067-1076, 1997.

WEINSTEIN RS, JILKA RL, PARFITT AM, MANOLAGAS SC: Inhibition of osteoblastogenesis and promotion of apoptosis of osteoblasts and osteocytes by glucocorticoids. Potential mechanisms of their deleterious effects on bone. J Clin Invest 102: 274-282, 1998.

WEINSTOCK-GUTTMAN B, GALLAGHER E, BAIER M, GREEN L, FEICHTER J, PATRICK K, MILLER C, WREST K, RAMANATHAN M: Risk of bone loss in men with multiple sclerosis. Mult Scler 10: 170-175, 2004.

ZORZON M, ZIVADINOV R, LOCATELLI L, GIUNTINI D, TONCIC M, BOSCO A, NASUELLI D, BRATINA A, TOMMASI MA, RUDICK RA, CAZZATO G: Long-term effects of intravenous high dose methylprednisolone pulses on bone mineral density in patients with multiple sclerosis. Eur J Neurol 12: 550$556,2005$. 